\title{
Concise Robust Control of Marine Engine Speed Based on Backstepping and Its Fuzzy Comprehension
}

\author{
Lijun Wang ${ }^{1,2}$ and Sisi Wang $\mathbb{D}^{2}$ \\ ${ }^{1}$ School of Navigation, Guangdong Ocean University, Zhanjiang 524088, China \\ ${ }^{2}$ Hubei Key Laboratory of Inland Shipping Technology, Wuhan 430063, China \\ Correspondence should be addressed to Sisi Wang; mars32lin@sina.com
}

Received 14 March 2019; Accepted 21 April 2019; Published 2 May 2019

Academic Editor: Basil M. Al-Hadithi

Copyright (c) 2019 Lijun Wang and Sisi Wang. This is an open access article distributed under the Creative Commons Attribution License, which permits unrestricted use, distribution, and reproduction in any medium, provided the original work is properly cited.

In this paper, a concise robust control law based on Backstepping for marine engine speed regulation is presented with the uniform asymptotic stability of the closed-loop system proved by Lyapunov synthesis, and the control parameters have obvious physical meaning. Furthermore, parameter determination method is given by virtue of closed-loop gain shaping algorithm. To overcome the perturbation due to load or interference change, variable universe fuzzy inference is introduced to optimize the control system on-line. Compared with the existing research literature, the design method and performance of the controller are more in line with the ocean engineering practice. The results of the simulations of the proposed controller are presented and compared.

\section{Introduction}

The speed regulation of marine main engine (MME) is related to its performance, service life, and ship safety. At present, the advanced MME speed governor is mostly based on PID digital controller [1-3]. There are typical nonlinearity, timevarying, uncertainty, and manual active intervention in the control process of ship main engine speed. Therefore, the traditional PID controller is difficult to obtain the optimal control performance $[4,5]$. An improved PID tuning method was proposed for marine diesel engine governors to overcome load fluctuation due to weather and sea conditions [1]. In order to improve the robustness of ship engine speed control, active disturbance rejection controller was presented in $[2$, $6]$, and robust control method was recommended in $[7,8]$. To optimize the control parameters, several intelligent algorithms have been used to achieve better control performance, such as fuzzy logic comprehension [3, 4], GA optimization [5], and Neural Network adaption [9].

Obviously, the current research mainly focuses on PID, robust, and intelligent algorithms; however, PID has poor self-adaptability, robust control is difficult to achieve in engineering, and intelligent algorithms often only have local optimal solutions. Inspired by previous studies, an optimal robust control system for marine engine speed regulation will be discussed in this paper. The main contributions of this work can be summarized as follows:

(i) The uniform asymptotic stability proof of a concise robust control design for the marine engine speed is given, and the control parameters are of obvious physical significance and can be determined easily

(ii) Variable universe fuzzy inference (VUFI) is recommended to solve the uncertainty caused by model perturbation and random disturbance for optimal control solution

The layout of the article is as follows: Section 2 presents a marine engine speed regulation model. Section 3 designs a concise robust controller and gives its stability proof. Section 4 provides online optimization of control parameters based on VUFI. Section 5 details the simulation results and discussion. Section 6 gives the conclusion.

\section{Marine Engine Speed Regulation Model}

2.1. Dynamic Model for Large Low Speed Marine Engines. This study is to design speed regulation controller for large low 
speed marine engines, such as MAN B\&M S60M. The second order dynamic model can be described as follows $[8,10,11]$.

$$
k T_{1} \dot{n}_{f}(t)+k n_{f}(t)=s(t-\tau)
$$

where $T_{1}$ is the time constant, $k$ is the amplification coefficient, $\tau$ is the dead time, and $n_{f}$ is the rate of revolution. And a nonlinear main engine model (NMEM) of transfer function form can be expressed as

$$
G_{N}(s)=\frac{n_{f}(s)}{p(s)}=\frac{e^{-\tau s}}{k T_{1} s+k}
$$

where $p$ is the fuel index position. The dead time is caused by the injection delay of the fuel system, which is estimated to be within the following range [1].

$$
\frac{15}{N_{f}}<\tau<\frac{15}{N_{f}}+\frac{60}{N_{f} \cdot Z}
$$

where $N_{f}$ is the rated speed and $Z$ is the number of engine cylinders. For large low speed marine engine, the delay term can be replaced by the following first order inertial expression:

$$
e^{-\tau s} \approx \frac{1}{\tau s+1}
$$

Consequently, the propulsion plant dynamics are described with the following equation on the s-plane. Note that all poles in $G_{N}(s)$ are real and stable.

$$
\begin{aligned}
G_{N}(s) & =\frac{1}{(\tau s+1)\left(k T_{1} s+k\right)} \\
& =\frac{1}{k \tau T_{1}(s+1 / \tau)\left(s+1 / T_{1}\right)}
\end{aligned}
$$

2.2. Actuating Mechanism. An electronic hydraulic actuator (EHA) controlled by a high-speed switch valve is used. The control signal is pulse width modulation, and the time delay of the link is not considered. The transfer function of the actuator can be described as follows:

$$
G_{A}(s)=\frac{1}{T_{2}^{2} s^{2}+2 \xi T_{2} s+1}
$$

where $T_{2}$ is the time constant and $\xi$ is the damping coefficient. In the ship's main engine operating system, the actuator has a displacement sensor, so it can be adjusted by feedback to make the output more stable.

\section{Control Design}

3.1. Concise Robust Control Design. In this section, a concise robust control law based on Backstepping for marine engine speed regulation is presented, and the control parameters have obvious physical meaning. Furthermore, parameter determination method is given.
Theorem 1. Considering the marine engine speed regulation model (1), the proposed controller (7) based on the Backstepping can stabilize the speed motion and guaranteeing the uniformly asymptotic stability of the closed-loop speed regulation system.

$$
\begin{aligned}
u= & \frac{1}{b}\left[-f\left(x_{2}\right)+\ddot{y}_{s e t}\right] \\
& -\frac{1}{b}\left[\left(1+k_{1} k_{2}\right) e+\left(k_{1}+k_{2}\right) e c\right]
\end{aligned}
$$

where e, ec are the speed error and its derivative, and $k_{1}, k_{2}$ are design parameters.

Proof. Set $x_{1}=n_{f}, x_{2}=\dot{n}_{f}, u=p$, and $y=x_{1}$, so we can obtain the state space model of (5) as follows:

$$
\begin{aligned}
\dot{x}_{1} & =x_{2} \\
\dot{x}_{2} & =f\left(x_{2}\right)+b u \\
y & =x_{1}
\end{aligned}
$$

where $f\left(x_{2}\right)=-\left(\left(\tau+T_{1}\right) / \tau T_{1}\right) x_{2}-\left(1 / \tau T_{1}\right) \int x_{2} d t, b=$ $1 / k \tau T_{1}$, and one defines the set revolution $y_{\text {set }}$ and the error variable $\eta_{1}$ :

$$
\eta_{1}=y-y_{\text {set }}=x_{1}-y_{\text {set }}
$$

The first Lyapunov function is selected as

$$
\begin{aligned}
& v_{1}=\frac{1}{2} \eta_{1}^{2} \\
& \dot{v}_{1}=\eta_{1} \dot{\eta}_{1}=\eta_{1}\left(\dot{x}_{1}-y_{r}\right)=\eta_{1}\left(x_{2}-y_{r}\right)
\end{aligned}
$$

Define virtual control variable $x_{2 d}=\dot{x}_{1}$, and assume

$$
\begin{gathered}
x_{2 d}=-k_{1} \eta_{1}+y_{\text {set }}, \\
\dot{v}_{1}=-k_{1} \eta_{1}^{2}<0
\end{gathered}
$$

where design parameters $k_{1}>0$, the function $v_{1}$ is negative definite, and one can get $\lim _{t \rightarrow \infty}\left(x_{1}-y_{\text {set }}\right)=0$; that is to say, the control of $x_{1}$ is realized.

Define another error variable $\eta_{2}$ and the second Lyapunov function $v_{2}$ :

$$
\begin{aligned}
& \eta_{2}=x_{2}-x_{2 d} \\
& v_{2}=\frac{1}{2} \eta_{1}^{2}+\frac{1}{2} \eta_{2}^{2}
\end{aligned}
$$

Substitute (8) and (12) in (14), so one can get

$$
\begin{aligned}
\eta_{2} & =\dot{x}_{1}-\dot{y}_{s e t}+k_{1} \eta_{1}=\dot{\eta}_{1}+k_{1} \eta_{1}, \\
\dot{v}_{2} & =-k_{1} \eta_{1}^{2}+\eta_{2}\left(\eta_{1}+\dot{x}_{2}-\dot{x}_{2 d}\right) \\
& =-k_{1} \eta_{1}^{2}+\eta_{2}\left[\left(1-k_{1}^{2}\right) \eta_{1}+k_{1} \eta_{2}+\dot{x}_{2}-\ddot{y}_{s e t}\right]
\end{aligned}
$$

To guarantee the negative definiteness of $v_{2}$, one can define a virtual control variable $x_{3 d}=\dot{x}_{2}$, and assume

$$
\begin{aligned}
x_{3 d} & =-\left(1-k_{1}^{2}\right) \eta_{1}-\left(k_{1}+k_{2}\right) \eta_{2}+\ddot{y}_{s e t}, \\
\dot{v}_{2} & =-k_{1} \eta_{1}^{2}-k_{2} \eta_{2}^{2}<0, \quad \forall k_{1} \neq 0, \quad k_{2} \neq 0
\end{aligned}
$$


where design parameters $k_{2}>0$, the function $v_{2}$ is negative definite, and one can get $\lim _{t \rightarrow \infty}\left(x_{2}-x_{2 d}\right)=0$; that is to say, the control of $x_{2 d}$ is realized by the control law (18), and all the variables in main engine speed control loop are uniformly asymptotic stable with equilibrium point $\left[x_{1}, x_{2}\right]=$ $\left[y_{\text {set }}, \dot{y}_{\text {set }}\right]$.

This ends the proof of Theorem 1.

Substituting (16) into (18), the control law is transformed as follows:

$$
x_{3 d}=-\left(1+k_{1} k_{2}\right) \eta_{1}-\left(k_{1}+k_{2}\right) \dot{\eta}_{1}+\ddot{y}_{\text {set }}
$$

Substituting (8) into (20), the actual control law was deduced, if

$$
\begin{aligned}
u & =\frac{1}{b}\left[-f\left(x_{2}\right)+\ddot{y}_{\text {set }}\right] \\
& -\frac{1}{b}\left[\left(1+k_{1} k_{2}\right) \eta_{1}+\left(k_{1}+k_{2}\right) \dot{\eta}_{1}\right] \\
& =\frac{1}{b}\left[-f\left(x_{2}\right)+\ddot{y}_{\text {set }}\right] \\
& -\frac{1}{b}\left[\left(1+k_{1} k_{2}\right)\left(x_{1}-y_{\text {set }}\right)+\left(k_{1}+k_{2}\right)\left(x_{2}-\dot{y}_{\text {set }}\right)\right] \\
& =\frac{1}{b}\left[-f\left(x_{2}\right)+\ddot{y}_{\text {set }}\right] \\
& -\frac{1}{b}\left[\left(1+k_{1} k_{2}\right) e+\left(k_{1}+k_{2}\right) e c\right] \\
& =-\frac{1}{b}\left[f\left(x_{2}\right)-\ddot{y}_{\text {set }}+u_{P D}\right]
\end{aligned}
$$

Remark 2. The essence of the control law (21) is to compensate the system's linearity or nonlinearity and to stabilize the control loop by a PD type controller $u_{P D}$. It is obvious that the Backstepping control design method is concise and effective. However, the design parameters $k_{1}, k_{2}$ are of little engineering significance and can only be determined by trial and error, which is not conducive to the robustness and optimization of the control performance.

3.2. Control Parameters Determination. In accordance with closed-loop gain shaping algorithm (CGSA) [12-17], a concise robust PID controller is presented as follows.

$$
\begin{aligned}
\frac{1}{T s+1} & =\frac{G C}{1+G C} \\
C & =\frac{1}{G T s} \\
G(s) & =\frac{\sigma}{\delta_{2} s^{2}+\delta_{1} s+\delta_{0}}
\end{aligned}
$$

where $G$ is the system transfer function model, $T$ stands for the system period, for the main engine speed control system, and $C$ is the design controller. Therefore, one can get a PID controller by substituting (24) into (23).

$$
C=\frac{\delta_{1}}{\sigma T}+\frac{\delta_{2} s}{\sigma T}+\frac{\delta_{0}}{\sigma T s}=K_{p}+K_{d} s+K_{i} \frac{1}{s}
$$

(5) can be transformed into (26). Obviously, (26) has the standard form as (24), which is of strictly rational proper fraction function.

$$
G_{N}(s)=\frac{1}{k \tau T_{1} s^{2}+\left(\tau+T_{1}\right) k s+k}
$$

On the basis of Theorem 1, the main engine speed steady-state error satisfies $\lim _{t \rightarrow \infty}\left(n_{f}-y_{\text {set }}\right)=0$. As a result, the integral term $K_{i} / s$ is negligible. Define $T_{M}$ as the system period, and substitute the parameters of (26) into (25), so one can get

$$
U_{P D}=K_{p}+K_{d} s=\frac{\tau+T_{1}}{T_{M}}+\frac{k \tau T_{1}}{T_{M}} s
$$

Remark 3. In accordance with ship main engine knowledge and the CGSA, the design parameters are of clear physical significance, which can be exactly determined. However, the control performance is not guaranteed to be adaptive to load changes and sea conditions.

\section{Parameter Online Tuning Based on VUFI}

A concise robust $\mathrm{PD}$ controller based on Backstepping and CGSA (CRPD-BC) is brought up with definite parameter determination method. However, when the control system model has perturbation due to load or interference change, the fixed control parameter often means the control performance might get worse. Therefore, the on-line optimization of control parameters is very important for the optimal and stable control performance. Consequently, an adaptive PD controller based on VUFI (APD-VUFI) is presented, which can adjust the fuzzy domain and precision of control parameters according to input and output, just as shown in Figure 1. Furthermore, it has better adaptive ability than general fuzzy PID [18-20]. Specific parameter adjustment rules are as shown in (28).

$$
\begin{aligned}
& K_{p}^{\prime}=K_{p}+\Delta_{K p}=K_{p}\left(1+O_{p}\right) \\
& K_{d}^{\prime}=K_{d}+\Delta_{K d}=K_{d}\left(1+O_{d}\right)
\end{aligned}
$$

Fuzzy comprehensive reasoning takes the form of two inputs and two outputs. $e, e c$ are the initial inputs and $\Delta_{K P}, \Delta_{K D}$ are the final outputs. According to the selection method of fuzzy scaling factor $[19,20]$, the domain scaling structure of fuzzy input $I_{e}, I_{e c}$ can be designed as follows:

$$
\begin{aligned}
& I_{e}=e \cdot \alpha(e)=e \cdot\left(\frac{|e|}{E}\right)^{\lambda 1} \\
& I_{e c}=e c \cdot \beta(e c)=e c \cdot\left(\frac{|e c|}{E C}\right)^{\lambda 2}
\end{aligned}
$$

where $e \in[-E, E], e c \in[-E C, E C], \lambda 1, \lambda 2 \in(0,1)$, and $\alpha, \beta$ are input regulation factors. At the same time, the domain scaling structure of fuzzy output $O_{p}, O_{d}$ is defined as follows.

$$
\gamma(t)=R[e, e c] P=R[e, e c]\left[p_{1}, p_{2}\right]^{\mathrm{T}}
$$

where $R$ is a proportional constant and $P$ is a constant vector. 


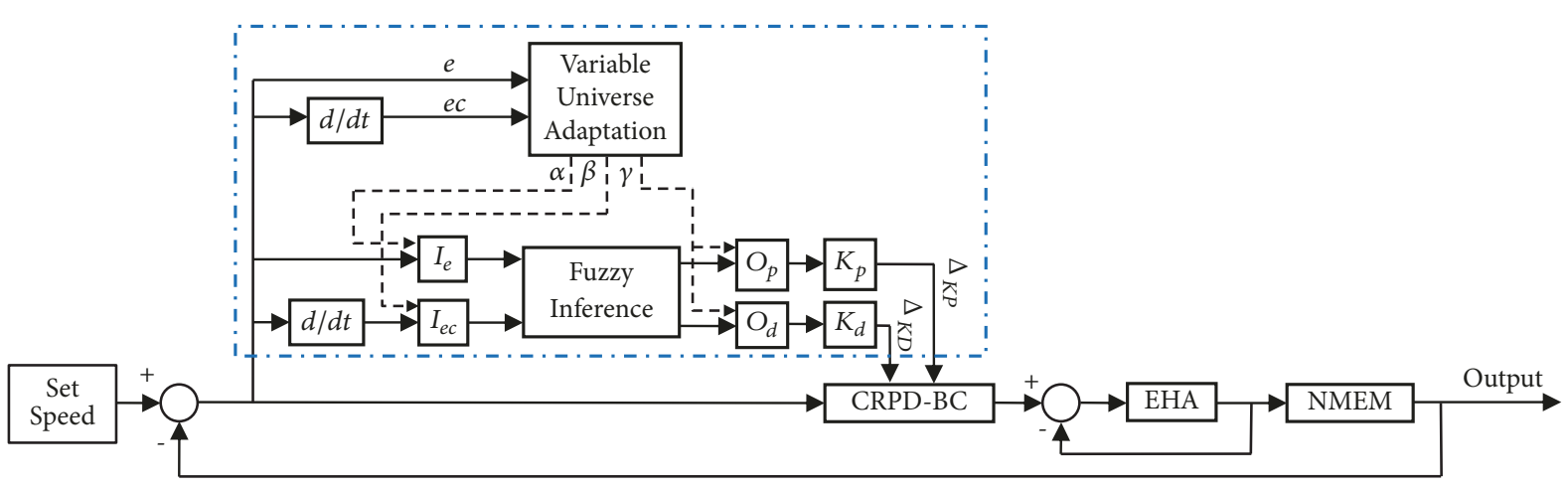

FIGURE 1: The control flow chart of robust fuzzy PD control of marine engine speed regulation.

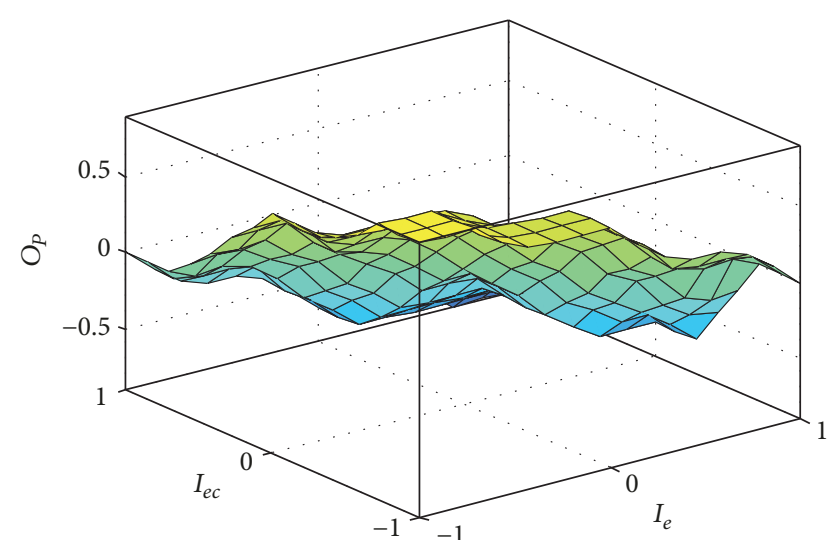

(a)

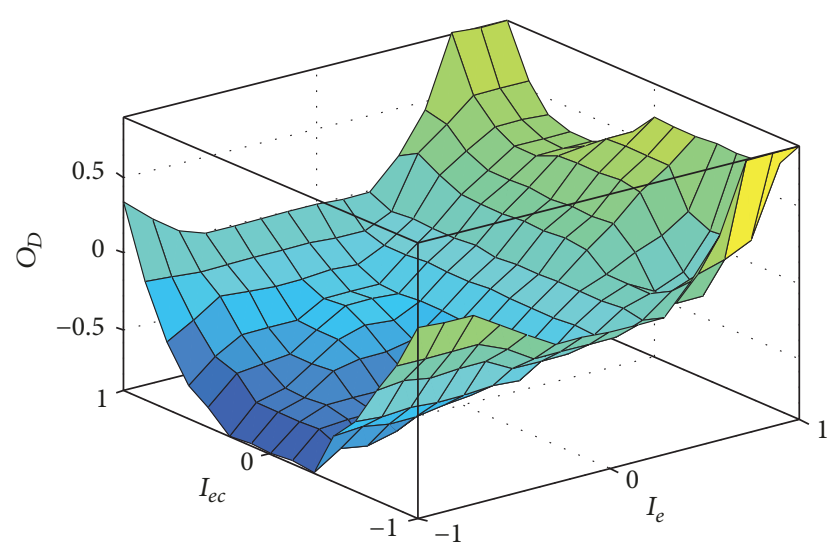

(b)

FIGURE 2: The surface views of fuzzy inference rules on $\Delta_{K P}(\mathrm{a})$ and $\Delta_{K D}$ (b).

The input and output of fuzzy reasoning are divided by triangular membership function with fuzzy linguistic variables $\mathrm{NB}, \mathrm{NM}, \mathrm{NS}, \mathrm{ZO}, \mathrm{PS}, \mathrm{PM}$, and $\mathrm{PB}$. According to the specific physical meaning and function of the control parameters, combined with field debugging and expert operation experience, the fuzzy control rules are shown in Figure 2.

\section{Simulation}

5.1. Simulation Configuration. In this section, the effectiveness of the presented control scheme in marine engineering practice is illustrated by several simulation examples. The simulation model described in Section 2 employs the parameters of MAN B\&M S60M, which is a widely used large low speed diesel engine. The time constant $T_{1}=12.1 \mathrm{~s}$, amplification coefficient $k=93.8$, pure delay time $\tau=$ $0.037 \mathrm{~s}$, when the model is perturbed, the above parameters are multiplied by $50 \%$. In the actuating mechanism, $T_{2}=$ $0.0307, \xi=0.704$. The speed of the ship's main engine is usually divided into four grades: dead slow, slow, half, and full, respectively, corresponding to $20,40,60$, and $80 \mathrm{rpm}$ in the simulation tests. It is assumed that the main engine speed is equal to the propeller speed. Furthermore, two kinds of interference are considered: the first is the sudden increase or decrease of load with an equivalent speed change of 10rpm, and the second is a sinusoidal wave interference, shown as follows:

$$
\begin{aligned}
& d_{s}=\lim _{n \longrightarrow \infty} \theta_{n}(t)= \begin{cases}0, & t<30 \\
10 \mathrm{rpm}, & 30 \leq t<80 \\
-10 \mathrm{rpm}, & t \geq 80\end{cases} \\
& d_{v}=A \sin (\omega t), \quad A=10, w=0.1 \pi
\end{aligned}
$$

The fuzzy domain scaling factors are $\lambda 1=\lambda 2=0.6, R=2$, and $\left[p_{1}, p_{2}\right]=[2,2]$.

5.2. Simulation Results and Discussion. The control performances of APD-VUFI under different settings of speeds and disturbances are shown in Figures 3-5, which indicate that the proposed control scheme can achieve good performances of speed regulation even in case of sudden load changing, sinusoidal wave interference, and model perturbations.

The speed regulation performances and fuel index positions at different set speeds are shown in Figure 3. It is clear that the performances of different rotating speeds meet the requirements. Moreover, it has typical quasi-linear transient performance without overshoot and good steady state performance. From the point of control input, big throttle is given 


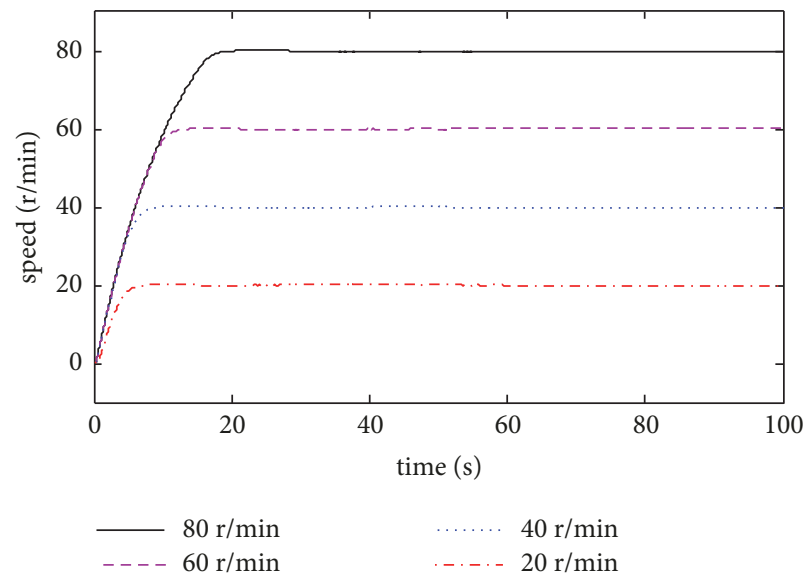

(a)

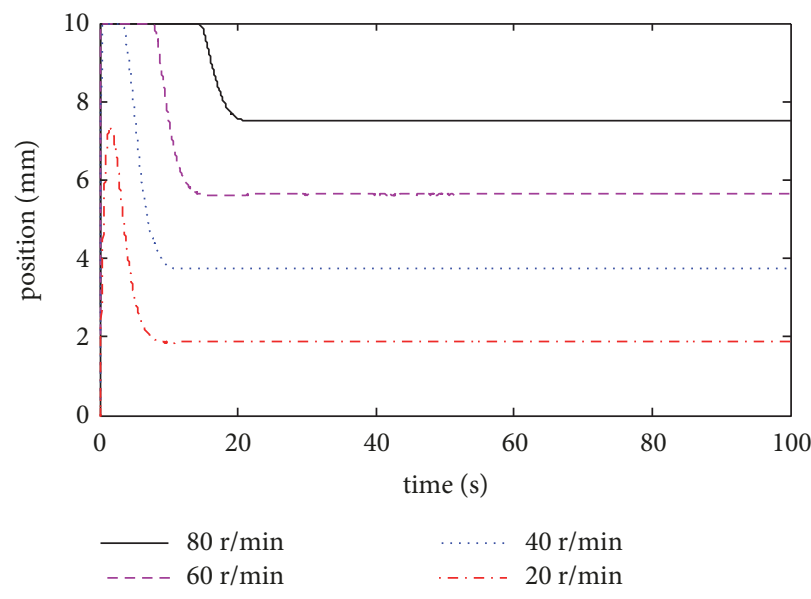

(b)

FIGURE 3: Speed regulation performances (a) and fuel index positions (b) at different set speeds.

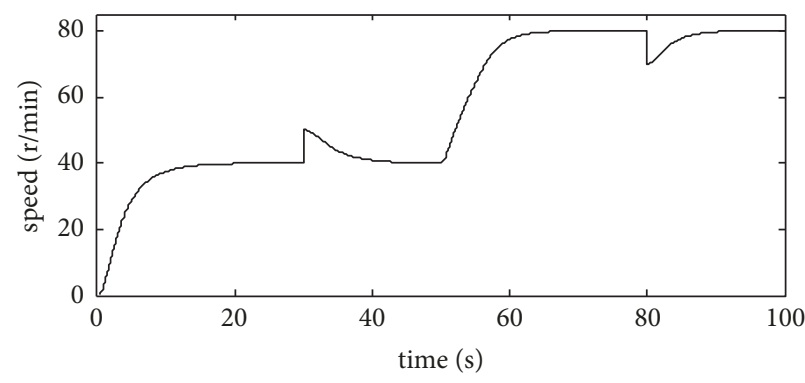

(a)

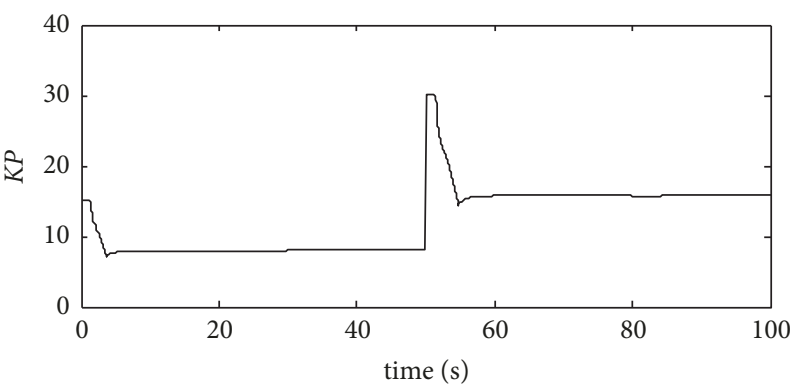

(c)

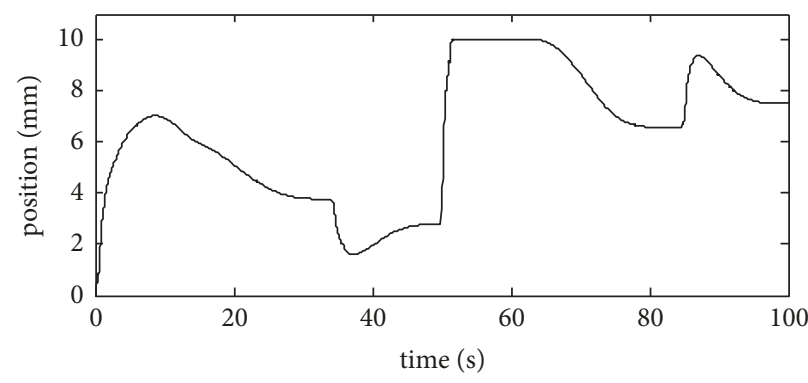

(b)

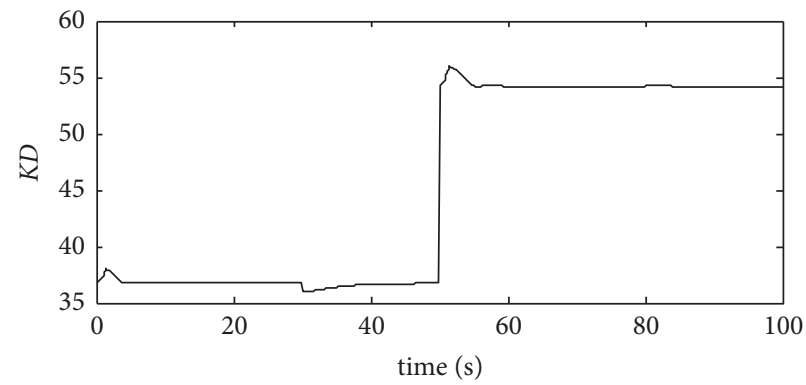

(d)

FIGURE 4: The speed regulation performances (a), fuel index positions (b), and adaptive variation of control parameters ((c)\&(d)) at different set speeds with sudden step disturbances.

firstly to speed up the start, and then the throttle is reduced at the right time to stabilize the speed at the set value, which is of typical engineering operation significance.

Figure 4 shows the control performance, control input, and control parameters adaptation in case of the set speed changing and even sudden load increases or decreases. Figure 4(a) indicates that the control system is well qualified for the above tasks. The control input in Figure 4(b) is reasonable, but there are some overshoots in the face of step type interference. At 30 seconds, the control input can be appropriately reduced when the load is suddenly reduced, so that the marine engine speed can be stabilized at the set value. Furthermore, it can be proved that the control system can also cope with sudden increase of load at 80 seconds. Figures 4(c) and 4(d) illustrate that the optimal control performance can be obtained by adjusting the control parameters under different set speed and different load conditions.

As shown in Figure 5(a), when faced with 50\% model perturbation, APD-VUFI performs better than CRPD-BC and traditional PD (TPD), CRPD-BC has the longest adjustment time, and TPD has certain overshoot. When there is sinusoidal wave interference $(>50 \mathrm{~s})$, APD-VUFI and CRPD$\mathrm{BC}$ can eliminate interference greatly, while TPC cannot. In terms of control rules, the control inputs given by APD-VUFI and CRPD-BC are similar, but APD-VUFI can provide larger 

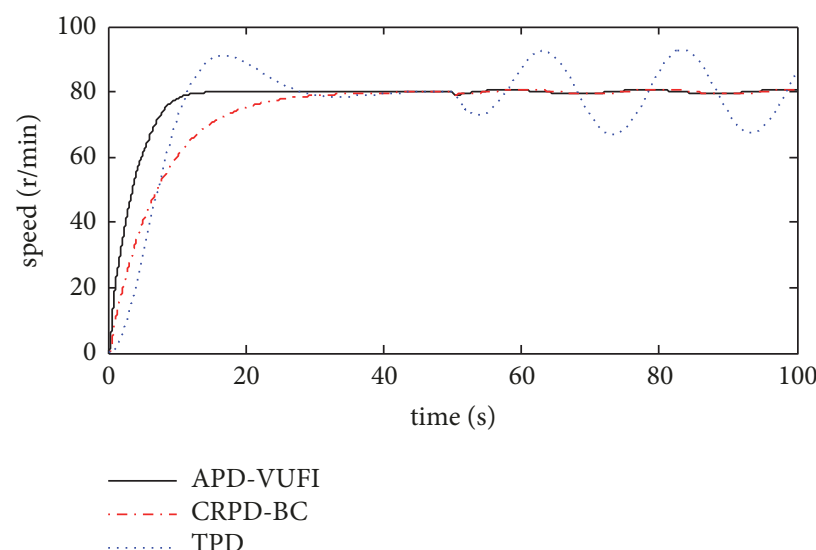
TPD

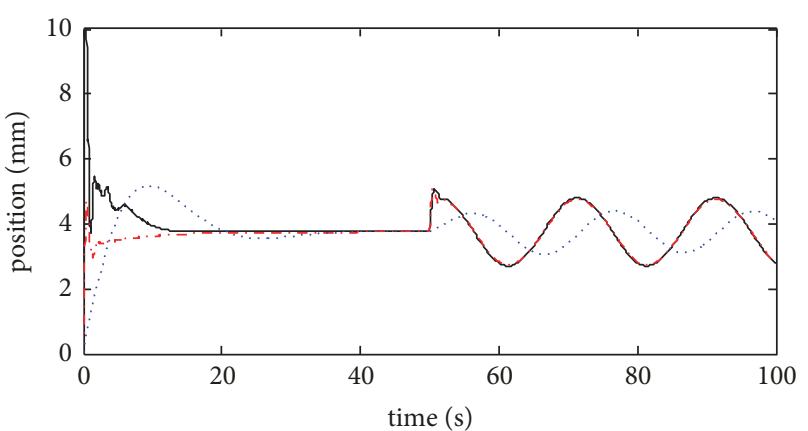

APD-VUFI

-...- CRPD-BC TPD

(a)

(b)

FIGURE 5: The comparison of speed regulation performances (a) and fuel index positions (b) by different controllers with a 50\% model perturbation and sinusoidal wave disturbances after 50 seconds.

input for quick startup, while TPD has smaller input and a certain phase delay in face of wave interference.

\section{Conclusion}

In this paper, one focuses on the optimal speed regulation for large low speed marine engines in field of engineering practice. A concise robust PID control law based on Backstepping is presented with the uniform asymptotic stability, and the control parameters have obvious physical meaning. Furthermore, parameter determination method is given by virtue of closed-loop gain shaping algorithm. To overcome the perturbation due to load or interference change, variable universe fuzzy inference is used to optimize the control system on-line. Compared with the existing research literature, the design method and performances are more in line with the ocean engineering practice. Simulation results have illustrated the performances and effectiveness of the proposed system.

\section{Abbreviations}

The abbreviations and symbols adopted throughout the paper are listed:

$\begin{array}{ll}\text { MME: } & \text { Marine main engine } \\ \text { GA: } & \text { Generic algorithm } \\ \text { VUFI: } & \text { Variable universe fuzzy inference } \\ \text { CGSA: } & \text { Closed-loop gain shaping algorithm } \\ \text { EHA: } & \text { Electronic hydraulic actuator } \\ \text { NMEM: } & \text { Nonlinear main engine model } \\ \text { RPM: } & \text { Revolutions per minute } \\ \text { TPD: } & \text { Traditional PD } \\ \text { APD-VUFI: } & \text { Adaptive PD controller based on VUFI } \\ \text { CRPD-BC: } & \text { Concise robust PD controller based on } \\ & \text { Backstepping and CGSA } \\ \text { PID: } & \text { Proportional integral derivative controller } \\ \text { PD: } & \text { Proportional derivative controller } \\ \text { T: } & \text { System period }\end{array}$

$T_{M}: \quad$ System period of marine engine speed system

$T_{1}$ : $\quad$ Time constant of marine engine speed system

$k$ : $\quad$ Amplification coefficient of marine engine speed system

$n_{f}: \quad$ Shaft speed of marine engine speed system

$p: \quad$ Fuel index position

$\tau: \quad$ Dead time of marine engine speed system

$Z: \quad$ Number of engine cylinders

$G$ : $\quad$ System transfer function model

$G_{N}$ : Transfer function of marine engine speed system

$G_{A}$ : Transfer function of electronic hydraulic actuator

C: $\quad$ Designed controller

$T_{2}$ : Time constant of electronic hydraulic

actuator

$\xi$ : $\quad$ Damping constant of electronic hydraulic

e: $\quad$ Speed error

ec: $\quad$ Speed error derivative

$u$ : The proposed controller

$U_{P D}: \quad$ PD type controller

$k_{1}, k_{2}$ : Design parameters of the controller

$y_{\text {set }}: \quad$ Set revolution

$\eta_{1}, \eta_{2}: \quad$ Set revolution errors

$x_{1}, x_{2}$ : State variables

$v_{1}, v_{2}$ : Lyapunov functions

$x_{2 d}, x_{3 d}$ : Virtual control variables

$\delta_{0}, \delta_{1}, \delta_{2}$ : Denominator parameters of a second order strictly rational proper system

$\sigma: \quad$ Numerator parameters of a second order strictly rational proper system

$k_{p}, k_{d}, k_{i}$ : Proportion, integration, and differentiation parameters

$k_{p}^{*}, k_{d}^{*}: \quad$ Adaptive proportion and differentiation parameters 


\begin{tabular}{|c|c|}
\hline$O_{p}, O_{d}:$ & $\begin{array}{l}\text { Fuzzy adjusting output factors of } \\
\text { proportion and differentiation parameters }\end{array}$ \\
\hline$\Delta_{K P}, \Delta_{K D}:$ & $\begin{array}{l}\text { Fuzzy outputs of the of proportion and } \\
\text { differentiation parameters }\end{array}$ \\
\hline$I_{e}, I_{e c}:$ & Fuzzy inputs \\
\hline$R, \lambda 1, \lambda 2:$ & Fuzzy domain scaling factors \\
\hline$P: \quad$ & Constant vector \\
\hline$\alpha, \beta:$ & Fuzzy input regulation factors \\
\hline$\gamma:$ & Fuzzy output regulation factor \\
\hline$[-E, E]:$ & Fuzzy domain of speed error \\
\hline$[-E C, E C]:$ & Fuzzy domain of speed error derivative \\
\hline$d_{s}:$ & $\begin{array}{l}\text { Disturbance due to sudden increase or } \\
\text { decrease of load with an equivalent speed } \\
\text { change }\end{array}$ \\
\hline$d_{v}:$ & Sinusoidal wave interference \\
\hline A: & Amplitude of sinusoidal wave interference \\
\hline$\omega:$ & Frequency of sinusoidal wave interference. \\
\hline
\end{tabular}

\section{Data Availability}

The authors obtain data from the third parties and therefore do not have the right to make that dataset publicly available. But data can be available upon request through the China Classification Society.

\section{Conflicts of Interest}

The authors declare that there are no conflicts of interest regarding the publication of this paper.

\section{Acknowledgments}

This work was supported by Fund of Hubei Key Laboratory of Inland Shipping Technology (Grant NHHY2018003); Scientific Research Start-up Funds of Guangdong Ocean University (Grants E15031 and R17012); Characteristic Innovation Projects of Guangdong Province (Grants 2017KTSCX088 and 2017KTSCX092); and College Student Innovation and Entrepreneurship Training Program of Guangdong Province (Grant 530002001095).

\section{References}

[1] N. I. Xiros, "PID marine engine speed regulation under full load conditions for sensitivity $\mathrm{H} \infty$-norm specifications against propeller disturbance," Journal of Marine Engineering and Technology, vol. 3, no. 2, pp. 3-11, 2004.

[2] W. Pan, H. Xiao, Y. Han et al., "Nonlinear active disturbance rejection controller research of main engine for ship," in Intelligent Control \& Automation, IEEE, 2010.

[3] X. Shen and Y. Su, "Marine diesel engine speed control system based on fuzzy-PID," Applied Mechanics and Materials, vol. 152154, pp. 1589-1594, 2012.

[4] T. A. Tran, "The optimization of marine diesel engine rotational speed control process by fuzzy logic control based on Particle swarm optimization algorithm," Future Internet, vol. 10, no. 10, pp. 1-18, 2018.
[5] V. Raval, "The rotation speed control of marine diesel engine," Journal of Automation and Automobile Engineering, vol. 2, no. 1, pp. 38-41, 2017.

[6] H.-D. Hua, N. Ma, J. Ma, and X.-Y. Zhu, "Robust intelligent control design for marine diesel engine," Journal of Shanghai Jiaotong University (Science), vol. 18, no. 6, pp. 660-666, 2013.

[7] G. Papalambrou and N. P. Kyrtatos, "Ho robust control of marine diesel engine equipped with power-take-in system," IFAC Proceedings Volumes, vol. 39, no. 12, pp. 591-596, 2006.

[8] M. Tuffaha and J. T. Gravdahl, "Modeling and control of a marine diesel engine driving a synchronous machine and a propeller," in Proceedings of the 2014 IEEE Conference on Control Applications, CCA 2014, pp. 897-904, France, October 2014.

[9] W. Meng and C. Guo, "Research on speed intelligent control based on neural networks for large marine main diesel engine," in Proceedings of the 2010 8th World Congress on Intelligent Control and Automation, WCICA 2010, pp. 4667-4670, July 2010.

[10] R. P. Sinha and R. Balaji, "A mathematical model of marine diesel engine speed control system," Journal of The Institution of Engineers, vol. 99, no. 2, pp. 1-8, 2017.

[11] H. M. Nahim, R. Younes, C. Nohra, and M. Ouladsine, "Complete modeling for systems of a marine diesel engine," Journal of Marine Science and Application, vol. 14, no. 1, pp. 93-104, 2015.

[12] L. Wang, S. Wang, J. Liu, and J. Han, "Robust pid control of course-keeping with RRS and its MCO based on NSGA-II," ICIC Express Letters, vol. 9, no. 11, pp. 3113-3119, 2015.

[13] X. Zhang, G. Yang, Q. Zhang, G. Zhang, and Y. Zhang, "Improved concise backstepping control of course keeping for ships using nonlinear feedback technique," Journal of Navigation, vol. 70, no. 6, pp. 1-14, 2017.

[14] X.-K. Zhang, Q. Zhang, H.-X. Ren, and G.-P. Yang, "Linear reduction of backstepping algorithm based on nonlinear decoration for ship course-keeping control system," Ocean Engineering, vol. 147, pp. 1-8, 2018.

[15] G. Zhang, Y. Deng, W. Zhang, and C. Huang, "Novel DVS guidance and path-following control for underactuated ships in presence of multiple static and moving obstacles," Ocean Engineering, vol. 170, pp. 100-110, 2018.

[16] G. Zhang, B. Tian, W. Zhang, and X. Zhang, "Optimized robust control for industrial unstable process via the mirror-mapping method," ISA Transactions $^{\circledR}$, vol. 86, pp. 9-17, 2019.

[17] S. Wang, L. Wang, Z. Qiao, and F. Li, "Optimal robust control of path following and rudder roll reduction for a container ship in heavy waves," Applied Sciences, vol. 8, no. 9, p. 1631, 2018.

[18] P. Hui, L. Fan, and X. Zeren, "Variable universe fuzzy control for vehicle semi-active suspension system with MR damper combining fuzzy neural network and particle swarm optimization," Neurocomputing, vol. 306, pp. 130-140, 2018.

[19] N. Arun and B. Mohan, "Modeling, stability analysis, and computational aspects of some simplest nonlinear fuzzy," ISA Transactions $^{\circledR}$, vol. 70, pp. 16-29, 2017.

[20] S. Askari, "A novel and fast MIMO fuzzy inference," Expert Systems with Applications, vol. 84, pp. 301-322, 2017. 


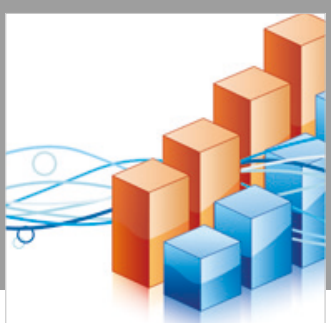

Advances in

Operations Research

\section{-n-m}
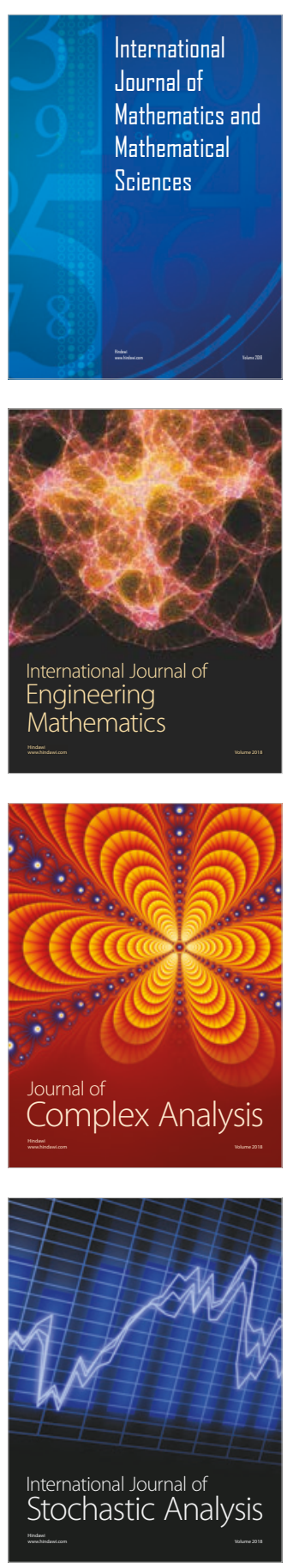
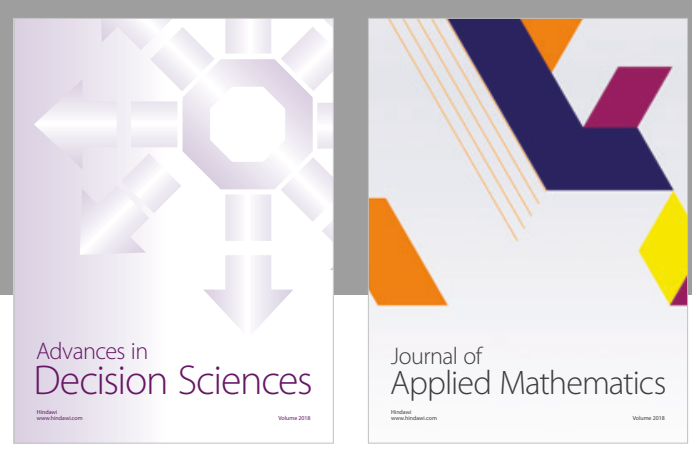

Journal of

Applied Mathematics
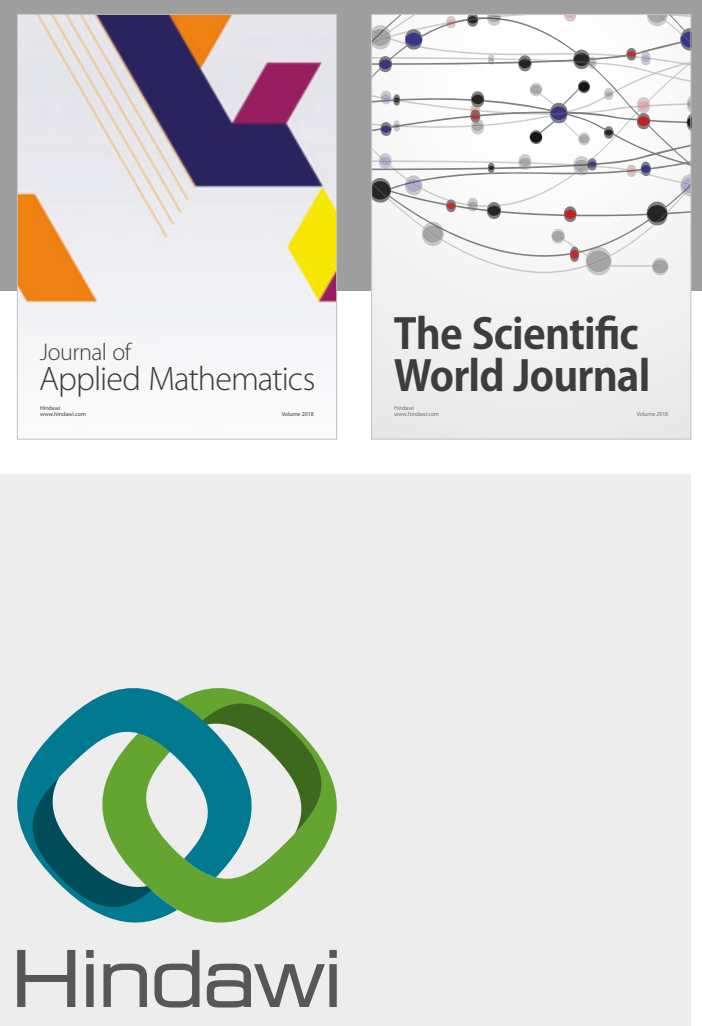

Submit your manuscripts at

www.hindawi.com

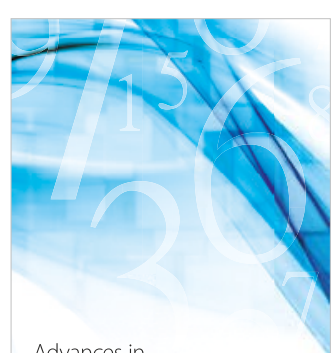

Advances in
Numerical Analysis
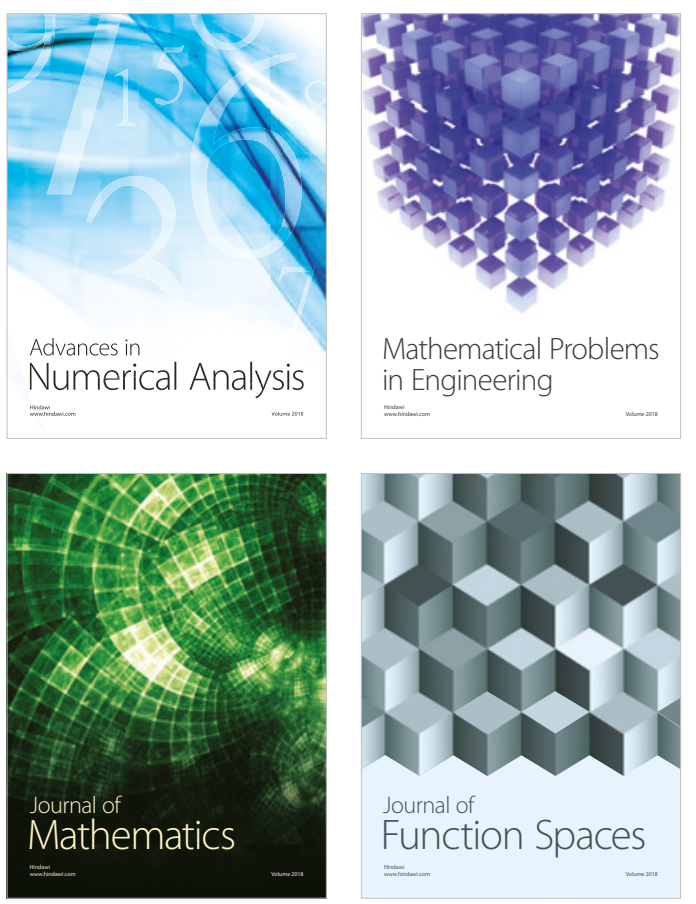

Mathematical Problems in Engineering

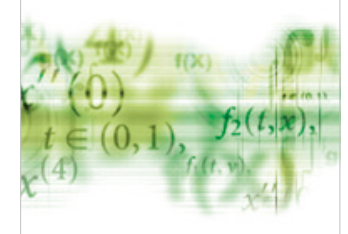

International Journal of

Differential Equations

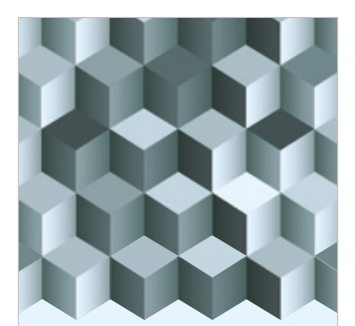

Journal of

Function Spaces
The Scientific

World Journal

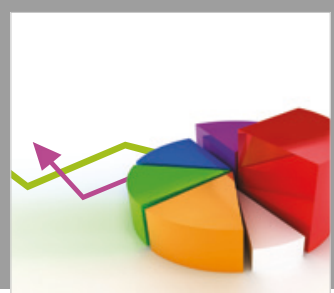

Journal of

Probability and Statistics
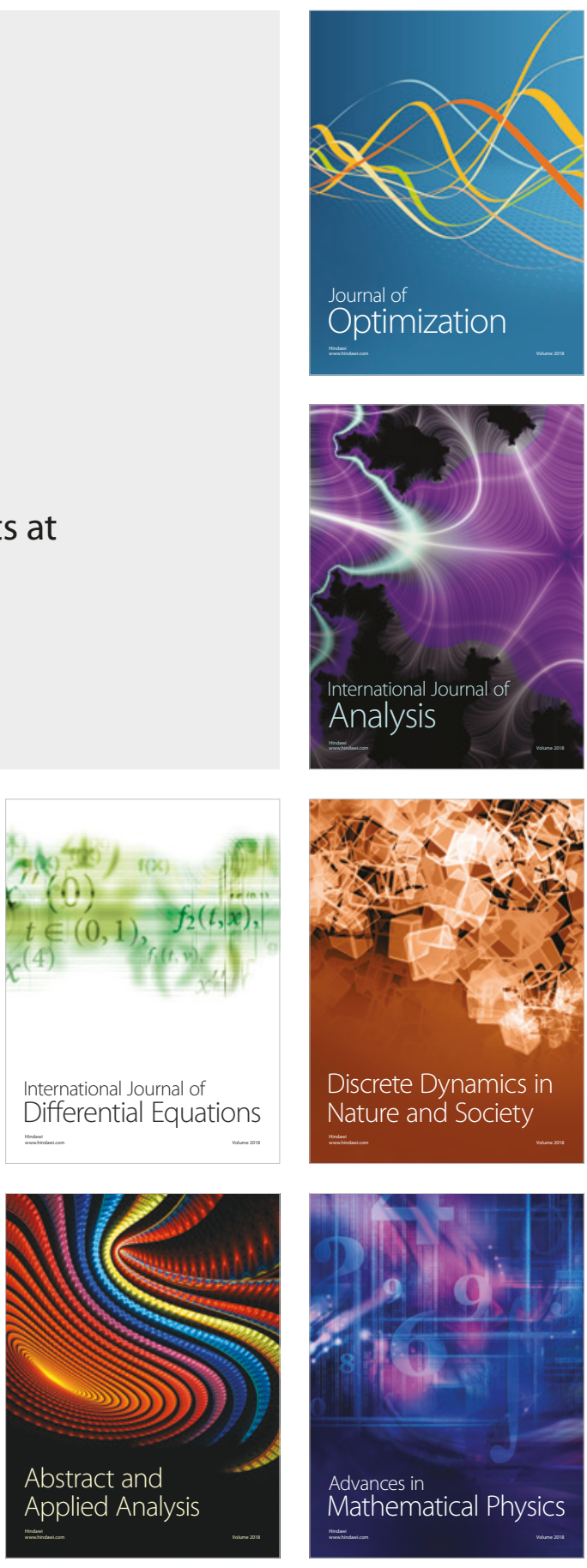